\title{
Asthma-like symptoms, atopy, and bronchial responsiveness in furniture workers
}

\begin{abstract}
Donatella Talini, Andrea Monteverdi, Alessandra Benvenuti, Marina Petrozzino, Francesco Di Pede, Maria Lemmi, Anna Carletti, Paola Macchioni, Nadi Serretti, Giovanni Viegi, Pierluigi Paggiaro
\end{abstract}

Cardiothoracic

Department and CNR Institute of Clinical

Physiology, Pisa, Italy A Benvenuti

M Petrozzino

F Di Pede

A Carletti

P Macchioni

G Viegi

P Paggiaro

Occupational Medicine Unit of Pisa, Italy

D Talini

N Serretti

Occupational Medicine Unit of Pontedera, Italy

A Monteverdi

M Lemmi

Correspondence to: Dr Donatella Talini, UO ISLL ASL No 5, via

Matteucci 34/B, 56100 Pisa, Italy.

Accepted 26 June 1998

\begin{abstract}
Objectives-To study the role of individual and occupational risk factors for asthma in furniture workers.

Methods-296 workers were examined (258 men, 38 women) with a questionnaire of respiratory symptoms and diseases, baseline spirometry, bronchial provocative test with methacholine, and skin prick tests. Non-specific bronchial hyperreactivity was defined as when a provocative dose with a fall of $20 \%$ in forced expiratory volume in 1 second $\left(\mathbf{P D}_{20} \mathrm{FEV}_{1}\right)$ was $<0.8$ $\mathrm{mg}$ and atopy in the presence of at least one positive response to skin prick tests. Workers were subdivided into spray painters (exposed to low concentrations of diisocyanates and solvents), woodworkers (exposed to wood dusts), and assemblers (control group).
\end{abstract}

Results-The prevalences of attacks of shortness of breath with wheezing and dyspnoea were higher in spray painters $(13.5 \%$ and $11.5 \%$ respectively) than in woodworkers $(7.7 \%$ and $6.3 \%)$ or in assemblers $(1.6 \%$ and $1.6 \%)$; prevalences of chronic cough, asthma, and rhinitis were also slightly but not significantly higher in spray painters and in woodworkers than in assemblers. The difference in the prevalence of respiratory symptoms among the job titles was due to the atopic subjects, who showed a higher prevalence of chronic cough, wheeze, shortness of breath with wheeze, dyspnoea, and asthma in spray painters than in the other groups. The prevalence of non-specific bronchial hyperreactivity in subjects who performed bronchial provocative tests was $17.7 \%$, with no significant difference among groups. Asthma symptoms were significantly associated with non-specific bronchial hyperreactivity. Asthma-like symptoms plus non-specific bronchial hyperreactivity was found in $4 \%$ of assemblers, $10 \%$ of woodworkers, and $13.3 \%$ of spray painters $\left(\chi^{2}=2.6\right.$, NS). Multiple logistic analysis taking into account individual (smoke, atopy, age) and occupational (job titles) risk factors confirmed that spray painters had higher prevalence of chronic cough than assemblers, and a trend in increasing the prevalence of shortness of breath with wheeze, dyspnoea, and asthma.

Conclusions-Painters in the furniture industry, particularly atopic subjects, are at higher risk of asthma-like symptoms than other job titles. In these workers asthma-like symptoms are more sensitive than non-specific bronchial hyperreactivity in detecting a negative effect of the occupational exposure.

(Occup Environ Med 1998;55:786-791)

Keywords: occupational asthma; furniture workers; toluene diisocyanate; wood dust

Exposure to irritants or sensitisers in the workplace can cause respiratory symptoms and bronchoconstriction by different pathophysiological mechanisms. ${ }^{1}$ Several types of occupational exposure are important determinants of asthma, ${ }^{2}$ but unfortunately there are few studies relating occupational risks with occurrence of asthma for several areas of employment and jobs. Epidemiological studies on the general population have shown that only a small group of working categories are at significant risk for occupational asthma. ${ }^{3}$

Furniture workers are exposed to several sensitisers or irritants-such as isocyanate vapours, wood dusts, and other chemicals (solvents, paints, phenol-formaldehyde resin dusts) - which may induce asthma; despite these data, studies and epidemiological research on respiratory effects in furniture workers are limited. ${ }^{45}$

Important environmental risk factors for occupational asthma are the level and the duration of exposure to specific agents in the workplace. Some studies have reported a correlation between these risk factors and indicators of occupational asthma. ${ }^{67}$ Predisposing host factors need to be considered in the pathogenesis of occupational asthma - such as atopy, tobacco smoke, and non-specific bronchial hyperreactivity. Atopy is a risk factor for sensitisation to high molecular weight compounds, although its predictive value is low. ${ }^{8}$ The effect of smoking is variable: it seems to interact with atopy and predisposes to sensitisation to high molecular weight compounds. ${ }^{9}$ Bronchial hyperreactivity often follows the development of occupational asthma, ${ }^{10}$ and there is no clear evidence that it can predispose subjects to sensitisation to occupational compounds.

Bronchial hyperreactivity may be considered the expression of the interaction between individual characteristics and exposure to different environmental factors, including occupational risks. ${ }^{11}$ However, Kremer et $a l^{12}$ reported that the association between exposure to irritants 
and respiratory symptoms was smaller for subjects with airway hyperreactivity than for subjects with normal airway responsiveness. Previous findings showed that bronchial hyperreactivity is not more sensitive that symptoms or forced expiratory volume in 1 second $\left(\mathrm{FEV}_{1}\right)$ in detecting pulmonary effects of occupational exposure, ${ }^{13}$ suggesting that bronchial hyperreactivity in epidemiological surveys is of limited value in identifying subjects with asthma. Our objective was to examine the prevalence and the distribution of chronic respiratory symptoms, level of lung function, and bronchial hyperresponsiveness to methacholine in a sample of furniture workers, and to identify the individual and occupational risk factors associated with the occurrence of symptoms of asthma and bronchial hyperreactivity.

\section{Methods}

STUDY DESIGN

All the furniture plants of an industrial district close to Pisa were subdivided into categories according to the number of the employees and a randomised sample of these plants was selected to obtain a consistent number of workers in each category. This sample was representative of the workers employed in the furniture industry of this area (about 600 plants employing 2200 workers), was stratified by the size of the plant, and 258 men and 38 women out of the 320 selected workers $(92.5 \%)$ took part to this cross sectional study.

STUDY POPULATION AND EXPOSURE GROUPS

The current exposure of the examined subjects was characterised on the basis of job titles and working department at the time of the survey.

Different work categories were considered and at least three environmental measurements with personal samples were available for each plant from people with different job titles. Gravimetric air sampling for total dusts was carried out. The sampling rate was about 3 $1 / \mathrm{min}$, and the minimum sampling duration was 5 hours. Most environmental measurements of exposure to toluene diisocyanate were collected with a toluene diisocyanate detector (continuous diisocyanates monitor, series 7100, MDA Scientific) placed near the operator (1-1.5 metres); the minimum sampling duration was 30 minutes. The concentration of solvents was recorded with Draeger vials.

The presence of ventilation was examined, and ventilation systems (system built specially for a technological cycle, forced general ventilation) or the use of personal protective equipment were recorded in the various plants. They were limited to some specific job taskssuch as spraying.

On the basis of job titles, the workers were divided into three groups:

\section{Woodworkers}

This group consisted of workers with exposure only to wood dust in furniture manufacturing (sawyers, carvers, cutters, and sanders). They were exposed to wood dust (mainly non-exotic woods - such as pine and beech. Personal sam- pling during some representative jobs showed weighted average concentrations of environmental particulate ranging from 0.11 to 9.0 $\mathrm{mg} / \mathrm{m}^{3}$ (mean (SD) $3.56(2.7) \mathrm{mg} / \mathrm{m}^{3}$, geometric mean: $\left.2.72 \mathrm{mg} / \mathrm{m}^{3}, \mathrm{n}=17\right)$.

\section{Spray painters}

This group consisted of workers employed in the finishing rooms, exposed to solvents and diisocyanate vapours but not to dusts. Monitoring of personal exposure to solvents showed weighted average concentrations of solvent vapours ranging from $1 / 50$ to $1 / 2$ of the threshold limit value (TLV) $(n=23)$. Toluene diisocyanate vapours showed a weighted average concentration ranging from 0.01 to $17 \mathrm{ppb}$ (mean (SD) 1.23 (1.6) ppb, geometric mean: 0.65 $\mathrm{ppb}, \mathrm{n}=16$ ).

\section{Assemblers}

This reference group consisted of workers employed in the assembling of the furniture, unexposed to either wood dust or finishes. None of them had previously worked in other jobs in the same or in previous furniture plants for $>6$ months.

\section{OUESTIONNAIRE}

Data on smoking, occupational risk factors, respiratory symptoms, and diseases were collected by trained interviewers with a modified Italian version of the standard National Heart and Lung Institute questionnaire (National Research Council questionnaire). ${ }^{14}$ It contains questions concerning respiratory symptoms, diseases, and risk factors.

Non-smokers were defined as those who had never smoked regularly. Smokers were those who were currently smoking at least one cigarette daily. Ex-smokers included those who had formerly smoked regularly, at least 6 months before the examination.

The following symptoms were considered for analysis and were taken into account if the diagnosis was confirmed by a physician: chronic cough (or phlegm), defined as cough (or phlegm) for as much as 3 months of the year for at least 2 years; wheeze, defined as wheeze apart from the common cold; dyspnoea, defined as for shortness of breath (grade $\geqslant 1$ ); shortness of breath with wheeze, defined as any attack of shortness of breath with wheeze, apart from the common cold; allergic rhinitis, defined as hay fever or any allergy making the nose runny or stuffy, apart from the common cold; chronic bronchitis, defined with affirmative answer to the question "Have you brought up phlegm from your chest on most days for $\geqslant 3$ consecutive months in the past 2 years ?"; and emphysema and asthma, defined with affirmative answer to the question "Have you ever had emphysema (or asthma)?"

\section{SPIROMETRY}

Spirometry was performed with a water sealed bell spirometer (Biomedin Alta 2, Padova, Italy) connected to a personal computer, according to the standard criteria. ${ }^{15} \mathrm{~A}$ minimum of three satisfactory forced expiratory manoeuvres was required of each subject. A 
satisfactory test required that the forced vital capacity (FVC) and $\mathrm{FEV}_{1}$ of two manoeuvres was reproducible within 5\%. Analyses were performed on the largest FVC and $\mathrm{FEV}_{1}$ expressed as percentage of the predicted value. ${ }^{16}$

BRONCHIAL PROVOCATIVE TEST WITH

METHACHOLINE

The test was performed on a working day, usually at the end of the workshift, and when baseline $\mathrm{FEV}_{1}$ was $>70 \%$ of the predicted value, according to the method previously described ${ }^{17}$ with methacholine solution $(0.4$ and $4 \% \mathrm{wt} / \mathrm{vol}$ in phosphate buffer solution). Methacholine was delivered by a DeVilbiss 646 jet nebuliser (DeVilbiss, Somerset, PA, USA) connected to a dosimeter driven by compressed air (Passerini, Pontedera, Italy). The nebuliser was filled with $3 \mathrm{ml}$ methacholine solution or diluent control. Phosphate buffered saline was inhaled first, followed every 2 minutes by methacholine inhalations in increasing doses. Two different protocols of methacholine inhalation were used: (a) in subjects without current or previous asthma symptoms (wheezing or asthma), methacholine concentration was $4 \% \mathrm{wt} / \mathrm{vol}$ (short protocol); the number of inhalations at each subsequent step was: $1+1+2+4$, and the cumulative doses were respectively $0.4,0.8,1.6$, and $3.2 \mathrm{mg}$ methacholine; $(b)$ in subjects with current or previous asthma symptoms, a full protocol with two methacholine concentrations (0.4 and $4 \%$ wt/vol) was used; the number of inhalations at each subsequent step were methacholine $0.4 \%$ : $1+2+3+4$; with methacholine $4 \%: 1+2+4$; and the cumulative doses were: $0.04,0.12,0.24$, $0.4,0.8,1.6$, and $3.2 \mathrm{mg}$ methacholine. The $\mathrm{FEV}_{1}$ was measured 2 minutes after each series of methacholine inhalation until it fell $>20 \%$ below the control value. Methacholine responsiveness was expressed as the cumulative dose producing a $20 \% \mathrm{FEV}_{1}$ fall from the baseline value $\left(\mathrm{PD}_{20} \mathrm{FEV}_{1}\right)$, and as the slope of the dose-response curve calculated as a percentage fall in $\mathrm{FEV}_{1}$ at the last dose divided by the total dose given. ${ }^{18}$

SKIN PRICK TEST

Skin testing was performed with a panel of 11 common allergens including mites, pollens, moulds, and danders. The results were evaluated after 20 minutes with measurement of the mean wheal diameter minus the negative control. The presence of a wheal to one or more of the allergens $>3 \mathrm{~mm}$ was considered as an evidence of atopy. ${ }^{19}$

DATA ANALYSIS

Prevalence of respiratory symptoms and diseases are reported as percentages. FVC, $\mathrm{FEV}_{1}$, and slope of the dose-response curve of methacholine challenge are expressed as mean (SD).

The response to the bronchial provocative test with methacholine was expressed as different categories of $\mathrm{PD}_{20} \mathrm{FEV}_{1}$ methacholine: (a) $<0.8 \mathrm{mg}$ (non-specific bronchial hyperreactivity; (b) 0.8-3.2 $\mathrm{mg}$ (intermediate reactivity); (c) $>3.2 \mathrm{mg}$ - that is, no positive response after the highest dose of inhaled methacholine (no reactivity). These cut off limits were derived from a study performed in a sample of the general population and were calculated by discriminant analysis of the response to the challenge in normal subjects and in the asthmatic group. ${ }^{20}$ The normal cut off limit for asthma was $0.8 \mathrm{mg}$ $\mathrm{PD}_{20} \mathrm{FEV}_{1}$ methacholine.

Statistical significance of the unadjusted differences in prevalence of symptoms and bronchial hyperreactivity between groups in contingency tables was assessed by $\chi^{2}$ analysis. A p value $<0.05$ was considered significant, and a $\mathrm{p}$ value $0.1-0.05$ was considered suggestive of a trend. The difference in FVC and $\mathrm{FEV}_{1}$ ( $\%$ of the predicted value) and in the slope of the methacholine dose-response curve among different groups of exposure were tested by analysis of variance (ANOVA), and a $p$ value $<0.05$ was considered significant.

Logistic regression was used to analyse the influence of some confounding factors (age, duration of exposure, smoking, atopy) on the prevalence of respiratory symptoms and abnormal pulmonary functions $\left(\mathrm{FEV}_{1}\right.$ and $\mathrm{PD}_{20} \mathrm{FEV}_{1}$ methacholine) in spray painters or in woodworkers in comparison with assemblers. The results are given in terms of odds ratios (ORs) with 95\% confidence intervals (95\% CIs). Dependent and independent variables were binary $(0=$ absence, $1=$ presence of the condition). Continuous variables (age, duration of exposure, $\mathrm{FEV}_{1}$ ) were transformed into categorical variables with the quartile distribution obtained from all subjects; in particular, the highest quartile (for age and duration of exposure) or the lowest quartile (for $\mathrm{FEV}_{1}$ ) was associated with the presence of the condition.

\section{Results}

We examined 296 workers (258 men; 38 women). Except for smoking habit, there were no significant differences in the main characteristics and in the prevalence of respiratory symptoms between men and women, although most chronic symptoms were reported in higher proportion in women than in men-for example, chronic cough: $6.5 \%$ in men, $12.5 \%$ in women $(p=0.08)$. Because of the low number of women, the analyses were done on men only.

Stratifying by job titles, prevalence rates of shortness of breath with wheeze and dyspnoea were higher in spray painters than in the other groups with different job exposure (table 1). Prevalences of chronic cough, asthma, and rhinitis were also slightly but not significantly higher in spray painters and in woodworkers than in assemblers. There were no differences in mean age, distribution of smoking habit, duration of employment, and prevalence of other respiratory symptoms and diseases. Atopy was found more often in woodworkers, but the difference was not significant.

The difference in the prevalence of respiratory symptoms among the different job titles was due to the atopic subjects, who showed a higher prevalence of chronic cough, wheeze, shortness of breath with wheeze, dyspnoea, and 
Table 1 Main characteristics and prevalence of respiratory symptoms in the examined male workers stratified by exposure group

\begin{tabular}{|c|c|c|c|}
\hline & Assemblers & Woodworkers & Spray painters \\
\hline $\mathrm{n}$ & 63 & 143 & 52 \\
\hline Age $(y$, mean $(S D))$ & $38(12.1)$ & $38.5(11.3)$ & $40.5(11.8)$ \\
\hline Length of employment (y, mean (SD)) & $20.16(13.4)$ & $18.2(11.9)$ & $20.4(11.8)$ \\
\hline$<20$ y $(\%)$ & 47.1 & 53.5 & 46.9 \\
\hline$>20$ y $(\%)$ & 52.9 & 46.5 & 53.1 \\
\hline \multicolumn{4}{|l|}{ Smoking habit $(\%)$ : } \\
\hline Non-smokers & 28.6 & 29.6 & 44.2 \\
\hline Ex-smokers & 22.2 & 28.2 & 17.3 \\
\hline Smokers & 49.2 & 42.3 & 38.5 \\
\hline Atopy (\%) & 19 & 31.9 & 15.4 \\
\hline Chronic cough (\%) & 1.6 & 9.7 & 5.8 \\
\hline Chronic phlegm (\%) & 6.3 & 9.7 & 5.8 \\
\hline Any wheeze $(\%)$ & 19.4 & 27.5 & 26.9 \\
\hline Any SOBWHZ (\%) & 1.6 & 7.7 & $13.5^{\star}$ \\
\hline Dyspnoea (\%) & 1.6 & 6.3 & $11.5^{\star}$ \\
\hline Rhinitis (\%) & 3.2 & 14 & 11.5 \\
\hline Chronic bronchitis (\%) & - & 1.4 & 2.0 \\
\hline Emphysema (\%) & 1.6 & 2.9 & 0 \\
\hline Asthma (\%) & 1.6 & 7.7 & 9.6 \\
\hline FVC (\% predicted, mean (SD)) & $98.9(15.1)$ & $98.7(14.3)$ & $100.2(14.1)$ \\
\hline FEV1 (\% predicted, mean (SD)) & $106.8(18.0)$ & $105.9(19.0)$ & $105.8(18.5)$ \\
\hline
\end{tabular}

$\star_{\mathrm{p}}<0.05$ among different job titles by $\chi^{2}$ test.

SOBWHZ=shortness of breath with wheeze.

asthma in spray painters with respect to the other groups. In non-atopic subjects, no significant difference among groups was found (table 2).

Mean values of FVC and $\mathrm{FEV}_{1}$ were normal and similar among groups with different work exposure.

Out of 258 male workers 206 (79.8\%) performed a bronchial provocative test with methacholine. Of the remaining 52 subjects, the test was not done because of low $\mathrm{FEV}_{1}$ value $(n=7)$, refuse to perform the test $(n=23)$, current infectious respiratory diseases $(n=20)$, regular bronchodilator treatment $(n=2)$. The prevalence of bronchial hyperreactivity

Table 2 Prevalence of respiratory symptoms among the different job titles in atopic and non-atopic subjects

\begin{tabular}{llll}
\hline & Assemblers & Woodworkers & $\begin{array}{l}\text { Spray } \\
\text { painters }\end{array}$ \\
\hline Atopic subjects: & 12 & 45 & 8 \\
n & 0 & 4.4 & $50^{\star \star}$ \\
Chronic cough (\%) & 0 & 8.7 & 0 \\
Chronic phlegm (\%) & 8.3 & 42.2 & $50^{\star \star}$ \\
Any wheeze (\%) & 0 & 13.3 & $62.5^{\star \star}$ \\
Any SOBWHZ (\%) & 8.3 & 6.5 & $37.5^{\star}$ \\
Dyspnoea (\%) & 0 & 15.5 & $50^{\star}$ \\
Asthma (\%) & 51 & 98 & 44 \\
Non-atopic subjects: & 5.9 & 6.1 & 22.7 \\
n & 5.8 & 10.2 & 6.8 \\
Chronic cough (\%) & 22 & 20.6 & 22.7 \\
Chronic phlegm (\%) & 2 & 5.1 & 4.5 \\
Any wheeze (\%) & 2 & 5.1 & 4.5 \\
Any SOBWHZ \%) & 2 & 4.0 & 2.3 \\
Dyspnea (\%) & & & \\
Asthma (\%) & & & \\
\hline
\end{tabular}

${ }^{\star \star} \mathrm{p}<0.001 ;{ }^{\star} \mathrm{p}<0.01$ among different job titles by $\chi^{2}$ test.

SOBWHZ=shortness of breath with wheeze.

Table 3 Prevalence of respiratory symptoms in groups of furniture workers with different degree of non-specific bronchial responsiveness (NSBH)

\begin{tabular}{llll}
\hline & \multicolumn{2}{l}{$P D_{20} F E V_{1}$ Methacholine $(m g)$} \\
\cline { 2 - 4 } & $<0.8$ & $0.8-3.2$ & $>3.2$ \\
\hline $\mathrm{n}$ & 36 & 45 & 125 \\
Chronic cough (\%) & 18.8 & 10.8 & $3.2^{\star}$ \\
Chronic phlegm (\%) & 18.8 & 10.8 & 6.5 \\
Any wheeze (\%) & 53.3 & 32.4 & $18.3^{\star}$ \\
Any SOBWHZ (\%) & 13.3 & 16.2 & $1.9^{\star}$ \\
Dyspnoea (\%) & 0 & 16.2 & 4.5
\end{tabular}

${ }^{\star} \mathrm{p}<0.05$ among groups of airway responsiveness by $\chi^{2}$ test. SOBWHZ=shortness of breath with wheeze.
$\left(\mathrm{PD}_{20} \mathrm{FEV}_{1}\right.$ methacholine $<0.8 \mathrm{mg}$ ) in subjects who performed the bronchial provocative test was $17.7 \%$. Symptoms suggestive of asthma (chronic cough, wheeze, attack of shortness of breath) were, not surprisingly, significantly associated with bronchial hyperreactivity (table 3). There was no difference in the distribution of bronchial reactivity categories among groups with different work exposure (\% of subjects with bronchial hyperreactivity: 20.0 in assemblers, 15.5 in woodworkers, and 22.2 in spray painters) and mean (SD) values of the slope of the dose-response curve to methacholine were similar in different groups (6.5 (6.9) in assemblers, 5.6 (6.7) in woodworkers, 5.7 (6.5) in spray painters, $\mathrm{p}=0.2$ by ANOVA).

When subjects who showed asthma-like symptoms (wheeze, shortness of breath with wheeze, or asthma) plus bronchial hyperreactivity $\left(\mathrm{PD}_{20} \mathrm{FEV}_{1}\right.$ methacholine $<0.8 \mathrm{mg}$ ) were considered, the prevalence was $4 \%, 10 \%$, and $13.3 \%$ in assemblers, woodworkers, and spray painters respectively ( $\chi^{2}$ test $2.6, \mathrm{NS}$ ).

To estimate the association of the various job titles with the presence of respiratory symptoms, taking into account several confounding factors, multiple logistic regression analysis with simultaneous adjustment for age, duration of exposure, smoking, and atopy (dependent variables) was used. Chronic cough was significantly associated with spray painting, when corrected by individual risk factors (table 4), whereas shortness of breath with wheeze, dyspnoea, and asthma showed a trend towards an increase in spray painters with respect to assemblers. Atopy was associated with symptoms of asthma (OR 19.4, p<0.001), and smoking with chronic cough, chronic phlegm, and wheeze (OR 18.3, $\mathrm{p}=0.05$; OR 5.1, $\mathrm{p}<0.05$; OR 2.5, $\mathrm{p}<0.05$, respectively). No difference in the prevalence of respiratory symptoms was found among groups of exposure when bronchial hyperreactivity $\left(\mathrm{PD}_{20} \mathrm{FEV}_{1}\right.$ categories or slope of the dose-response curve) was included in the analysis as a dependent variable. 
Table 4 Estimated ORs (95\% CIs) for the prevalence of respiratory symptoms and functional abnormalities by job titles: reference category was assemblers (other variables included in the analysis were: age, duration of occupational exposure, atopy, and smoking habit (current smokers + ex-smokers $v$ non-smokers)

\begin{tabular}{|c|c|c|c|c|c|c|}
\hline & \multicolumn{3}{|c|}{ Woodworkers } & \multicolumn{3}{|c|}{ Spray painters } \\
\hline & OR & $95 \% C I$ & $p$ Value & OR & $95 \% C I$ & pValue \\
\hline Chronic cough & 1.5 & $(0.4$ to 6.6$)$ & NS & 4.3 & (0.9 to 19.7$)$ & $<0.05$ \\
\hline Chronic phlegm & 3.4 & (0.9 to 13.1$)$ & 0.07 & 1.9 & (0.4 to 9.4$)$ & NS \\
\hline Any wheeze & 1.3 & (0.6 to 3.1$)$ & NS & 1.2 & (0.4 to 3.2$)$ & NS \\
\hline Any SOBWHZ & 3.1 & (0.4 to 29.0$)$ & NS & 7.4 & (0.8 to 70.3$)$ & 0.07 \\
\hline Dyspnoea & 3.0 & (0.4 to 29.9 ) & NS & 6.6 & (0.7 to 66.7$)$ & 0.09 \\
\hline Asthma & 3.7 & $(0.5$ to 35.6$)$ & NS & 6.0 & (0.7 to 60.5$)$ & NS \\
\hline $\mathrm{FEV}_{1}<89.4 \%$ & 0.5 & $(0.2$ to 1.9$)$ & NS & 0.7 & $(0.2$ to 3.1$)$ & NS \\
\hline $\mathrm{PD}_{20} \mathrm{FEV}_{1}<0.8 \mathrm{mg}$ & 0.6 & (0.3 to 1.6$)$ & NS & 1.2 & (0.5 to 3.6$)$ & NS \\
\hline
\end{tabular}

SOBWHZ=shortness of breath with wheeze.

\section{Discussion}

Our results indicate that spray painters in the furniture industry are at higher risk for chronic respiratory symptoms suggestive of asthma than other job titles, particularly in atopic subjects. When other individual risk factors were taken into account, spray painters showed a significantly higher prevalence of chronic cough, and a trend to show higher prevalence of attacks of shortness of breath, dyspnoea, and asthma, than the reference group of assemblers.

Few data on asthma-like symptoms in spray painters of the furniture industry have been published. Previous papers reported a higher risk of asthma attributable to occupational exposure in spray painters, ${ }^{21}$ but these subjects were exposed to different chemical compounds. In a cross sectional epidemiological study in a sample of furniture workers exposed to isocyanate paints, ${ }^{5}$ the risk of asthma in the exposed group was almost five times the risk in non-exposed subjects. On the other hand, epidemiology of asthma symptoms in workers exposed to isocyanates has been extensively reported $^{22}$; in these cases, the prevalence of asthma-like symptoms was similar to that found in our group of furniture spray painters. Concentrations of various chemical compounds in the spray painting area of the furniture industry that we studied were lower than the threshold limit values both for isocyanates and solvents. However, we are not aware of the concentrations of these compounds in the previous years. ${ }^{23}$

Other papers have focused on the exposure to wood dust in furniture workers, ${ }^{4}$ showing a negative effect of dust exposure on respiratory symptoms and pulmonary function. Occupational exposure to western red cedar dust has been proved to be associated with higher prevalence of respiratory symptoms and pulmonary impairment. ${ }^{24}$ In our study, woodworkers did not show a significantly different prevalence of respiratory symptoms than the assemblers, despite the wide range of occupational exposure to dust. This fact could be ascribed to the type of the wood (non-exotic $v$ exotic wood) used in the furniture industry or to the lack of measurements on the respirable fraction of the wood dusts which limits a full evaluation of the respiratory risk in this group of workers.

Individual risk factors represent additional risk factors for respiratory disorders in these workers. Atopy was associated with symptoms of asthma, whereas smoking was significantly associated with chronic cough, chronic phlegm, and wheeze. Assessment of atopy of subjects in studies of occupational asthma is relevant as atopic subjects are more prone to sensitisation by high molecular weight agents, ${ }^{25}{ }^{26}$ although the positive predictive value in occupational asthma is generally low. ${ }^{25}{ }^{27}$ It is of interest that atopic spray painters reported higher prevalences of respiratory symptoms than atopic assemblers, and that this difference disappeared when non-atopic subjects were considered. Atopy has not been considered an important risk factor for occupational asthma in workers exposed to simple chemicals - such as isocyanate-but this fact has not been supported by epidemiological data. ${ }^{28}$

Workers with higher occupational risk differed from non-exposed subjects by asthmalike symptoms and not by the prevalence of bronchial hyperreactivity. Questionnaires given by trained physicians have been proved to have variable sensitivity and low specificity in predicting asthma or occupational asthma. Enarson $e a^{13} l^{13}$ studied the association between the degree of non-specific bronchial hyperreactivity with various definitions of asthma and asthma-like symptoms, and found that measurement of non-specific bronchial hyperreactivity by itself is of limited value in identifying subjects with asthma; symptoms most suggestive of asthma were, not surprisingly, most closely associated with bronchial hyperexcitability. Furthermore, bronchial hyperresponsiveness did not seem to add information to the data from the questionnaire or $\mathrm{FEV}_{1}$ in the evaluation of the risk factors for respiratory disorders, ${ }^{24}{ }^{29}$ and other studies do not provide support for the hypothesis that bronchial responsiveness alone may be an identifying feature of a more susceptible group of workers. ${ }^{11}$

In our experience non-specific bronchial hyperreactivity did not distinguish between different job titles, and when it was included in the logistic analysis as a dependent variable, no significant association between work exposure and asthma symptoms was detected. This lower potency of bronchial hyperreactivity than asthma-like symptoms in detecting the effect of occupational exposure could be due to several confounding factors. Firstly, the prevalence of atopy in the workers examined seemed some- 
times to be lower than in the general population, although no significant difference was found among groups with different job titles. This fact could indicate some selection of the workers, with susceptible subjects having moved to different work categories. Secondly, hyperreactive subjects could have been moved from a working area at higher risk to another with lower risk. All subjects we examined had worked out of the present working area for $<6$ months, and this seems negligible in comparison with the long duration of employment (about 20 years). Symptoms could be reported more often by spray painters because they were aware of their exposure to some occupational respiratory risks. However, the association of asthma-like symptoms and bronchial hyperreactivity showed a trend to increase from assemblers to spray painters, although the difference was not significant. Finally, the size of our sample could be too small to detect a significant difference in bronchial hyperreactivity between workers with different job exposure. Other authors have studied groups of workers with the same job exposure profile and similar or lower group sizes than our workers, ${ }^{12} 31$ and some of them found significant differences among groups. However, the exclusion of subjects with respiratory abnormalities from the work place (the so called healthy worker effect) and the small sample size could have determined a low potency of the study in detecting more relevant differences among groups with different work exposure.

The aim of our study was not to evaluate the prevalence of occupational asthma, because no assessment was performed of specific sensitisation to occupational compounds or any relation between symptoms and specific occupational exposure-for example, by monitoring peak expiratory flow. In two subjects only occupational asthma had been previously diagnosed; these two subjects were under regular treatment with antiasthma drugs, and they did not perform a methacholine challenge. They were not included in the analysis of bronchial hyperreactivity.

The $\mathrm{FEV}_{1}$ and FVC were not different among groups of different job titles. This showed a lower sensitivity than symptoms in detecting the effect of occupational exposure. This finding has been already reported, ${ }^{12}{ }^{30}$ and it could be ascribed to a biological effect of the inhaled irritants on the airways without a chronic persistent change in pulmonary function.

In conclusion, we showed that painters in the furniture industry particularly those with atopy, are at higher risk of asthma-like symptoms than are men with other jobs. In this group of workers, non-specific bronchial hyperreactivity does not seem to add further information to the data gained from the questionnaire in the evaluation of the risk factors for respiratory disorders.

1 Becklake MR. Epidemiology: Prevalence and determinants. In: Bernstein IL, Chan-Yeung M, Malo JL, et al, eds.
Asthma in the workplace. New York: Marcel Dekker, 1993:29-59.
2 Chan Yeung M, Malo JL. Aetiological agents in occupational asthma. Eur Respir f 1994;7:346-71.

3 Krzyzanowski M, Kauffmann F. The relation of respiratory symptoms and ventilatory function to moderate occupational exposure in a general population: results from the French PAARC study of 16000 adults. Int $\mathcal{F}$ Epidemiol 1988;17:397-406.

4 Goldsmith DF, Shy CM. An epidemiological study of respiratory health effects in a group of North Carolina furniture workers. f Occup Med 1988;30:959-65.

5 Mastrangelo G, Paruzzolo P, Mapp C. Asthma due to isocyanates: a mail survey in a $1 \%$ sample of furniture workers in the Veneto Region, Italy. Med Lav 1995;86:50310.

6 Musk AW, Venables KM, Crook B, et al. Respiratory symptoms, lung function, and sensitisation to flour in a British bakery. Br f Ind Med 1989;46:636-42.

7 Cullinan P, Lowson D, Nieuwenhuijesen MJ, et al. Work related symptoms, sensitisation and estimated exposure in workers not previously exposed to laboratory rats. Occup Environ Med 1994;51:589-92.

8 Dosman JA, McDuffie HH, Pahwa P. Atopic status as a factor in job decision making in grain workers. $f$ Occup Med 1991;9:1007-10.

9 Venables KM, Topping MD, Howe W, et al. Interaction of smoking and atopy in producing specific $\operatorname{IgE}$ antibody against a hapten protein conjugate. BMf 1985;290:201-4.

10 Chan-Yeung M, Desjardins A. Bronchial hyperresponsiveness and level of exposure in occupational asthma due to western red cedar (Thuja plicata). Serial observations before and after development of symptoms. Am Rev Respir Dis 1992;146:1606-9.

11 Postma DS, Koeter GH, Sluiter HJ. Pathophysiology of airway hyperresponsiveness. In: Weiss ST, Sparrow D, eds. Airway responsiveness and atopy in the development of chronic lung disease, New York: Raven Press, 1990;21-72.

12 Kremer AM, Pal TM, Boleij JSM, et al. Airway hyperresponsiveness, prevalence of chronic respiratory symptoms, and lung function in workers exposed to irritants. Occup Environ Med 1994;51:3-13.

13 Enarson DA, Vedal S, Schulzer M, et al. Asthma, asthmalike symptoms, chronic bronchitis, and the degree of bronchial hyperresponsiveness in epidemiologic surveys. Am Rev Respir Dis 1987;136:613-7.

14 Viegi G, Paoletti P, Prediletto R, et al. Prevalence of respiratory symptoms in an unpolluted area of northern Italy. Eur Respir f 1988;1:311-8.

15 American Thoracic Society. Standardization of spirometry: 1987 update. Am Rev Respir Dis 1987;136:1285-98.

16 Paoletti P, Pistelli G, Fazzi P, et al. Reference values for vital capacity and flow-volume curves from a general population study. Bull Eur Physiopathol Respir 1986;22:451-9.

17 Paggiaro PL, Vagaggini B, Dente FL, et al. Bronchial hyperresponsiveness and toluene diisocyanate. Long-term change in sensitized asthmatic subjects. Chest 1993;103: 1123-8.

18 O'Connor GT, Sparrow D, Taylor D, et al. Analysis of doseresponse curves to methacholine: an approach suitable for population studies. Am Rev Respir Dis .1987;136:1412-7.

19 Bapulation studies. Am Rev Respir Dis .1987;136:1412-7. tivity to common aeroallergens in relation to total IgE, respiratory symptoms, and smoking in a general population sample of northern Italy. Allergy 1996;51:149-56.

20 Bruschi C, Cerveri I, Zoia MC, et al. Bronchial responsiveness to inhaled methacholine in epidemiological studies: comparison of different indices. Eur Respir f 1989;2:630-6.

21 Kogevinas M, Antò JM, Soriano JB, et al. The risk of asthma attributable to occupational exposures. A population-based study in Spain. Am $\mathcal{F}$ Respir Crit Care Med 1996;154:13743.

22 Bernstein IL. Isocyanate-induced pulmonary disease: a current perspective. F Allergy Clin Immunol 1982;70:24-31.

23 Venables KM. Prevention of occupational asthma. Eur Respir f 1994;7:768-78.

24 Chan Yeung M, Vedal S, Kus J, et al. Symptoms, pulmonary function and bronchial hyperreactivity in western red cedar workers compared with those in office workers. Am Rev Respir Dis 1984;130:1038-41.

25 Slovak AJM, Hill RN. Laboratory animal allergy: a clinical survey of an exposed population Br f Ind Med 1981;38:3841 .

26 Enarson DA, Chan-Yeung M, Tabona M, et al. Predictors of bronchial hyperexcitability in grainhandlers. Chest 1985;87: $452-5$.

27 Malo JL, Cartier A, L'Aercheveque J, et al. Prevalence of occupational asthma and immunologic sensitization to psyllium among health personnel in chronic care hospitals. Am Rev Respir Dis 1990;142:1359-66.

28 Mapp CE, Boschetto P, Dal Vecchio L, et al. Occupational asthma due to isocyanate. Eur Respir f 1988;1:273-9.

29 Vedal S, Enarson DA, Chan H, et al. A longitudinal study of the occurrence of bronchial hyperresponsiveness in western the occurrence of bronchial hyperresponsiveness in west

30 Dales RE, Spitzer WO, Suissa S, et al. Respiratory health of a population living downwind from natural gas refineries. Am Rev Respir Dis 1989;139:595-600.

31 Malmberg PO, Rask-Andersen A, Larsson KA, et al. Increased bronchial responsiveness in workers sawing scots pine. Am f Respir Crit Care Med 1996;153:948-52. 